\title{
An unusual case of primary hyperparathyroidism in a patient with concomitant familial hypocalciuric hypercalcaemia
}

\author{
Sagi SV, Okafor MAC, Oyibo SO, Rajkanna J \\ Department of Endocrinology, Peterborough City Hospital, Peterborough, UK
}

\section{INTRODUCTION}

Familial hypocalciuric hypercalcemia $(\mathrm{FHH})$ is a benign condition characterized by asymptomatic hypercalcemia, relative hypocalciuria and variable parathyroid hormone levels. It is caused by a loss-of-function mutation in the calcium-sensing receptor (CASR) gene. The occurrence of both FHH and primary hyperparathyroidism (PHPT) in the same patient has rarely been described. We report an interesting case highlighting the challenges involved in diagnosis and management.

\section{CASE}

A 71 year old lady was reviewed because of severe hypercalcaemia. This was discovered during routine screening because of a family history of FHH and the presence of the CASR gene mutation. She was asymptomatic. She had no relevant past medical history and was not taking any medication, calcium or vitamin $\mathrm{D}$ supplements.

\section{INVESTIGATION AND MANAGEMENT}

Blood results indicated mild chronic kidney disease and normal vitamin D levels, raised serum calcium (3.24mmol/L), low serum phosphate $(0.67 \mathrm{mmol} / \mathrm{L})$ and a slightly raised parathyroid hormone $(11.9 \mathrm{pmol} / \mathrm{L})$. Her 24-hour urinary calcium excretion was inappropriately low at $2.2 \mathrm{mmol}$ with a fractional excretion of calcium of 0.0052 confirming hypocalciuria in the presence of hypercalcaemia. Genetic testing confirmed the presence of the CASR gene mutation [c.2444A $>G$, p.(Lys815Arg)]. However, the disproportionately high serum calcium level prompted further investigation. Her bone density scan showed osteopenia. An ultrasound and parathyroid MIBI scan (Figure 1) detected a right lower pole parathyroid adenoma. After informed discussion she underwent parathyroidectomy (histology confirmed a parathyroid adenoma). Immediately post-operatively her calcium fell down to $2.51 \mathrm{mmol} / \mathrm{L}$ (Table 1 ) and then rose back to 2.77 $\mathrm{mmol} / \mathrm{L}$. Her parathyroid hormone level also fell down to $0.8 \mathrm{pmol} / \mathrm{L}$ then rose back to $2.9 \mathrm{pmol} / \mathrm{L}$, both indicating continued mild hypercalcaemia of $\mathrm{FHH}$.

Table 1

\begin{tabular}{|l|c|c|c|}
\hline & $\begin{array}{c}\text { Pre-operative } \\
\text { period }\end{array}$ & $\begin{array}{c}\text { Post-operative } \\
\text { period }\end{array}$ & Latest Results \\
\hline $\begin{array}{l}\text { Adjusted Calcium } \\
(2.2-2.6 \mathrm{mmol} / \mathrm{l})\end{array}$ & 3.24 & 2.48 & 2.77 \\
\hline $\begin{array}{l}\text { Parathormone } \\
(1.4-6.2 \mathrm{pmol} / \mathrm{l})\end{array}$ & 11.9 & 0.8 & 2.9 \\
\hline
\end{tabular}

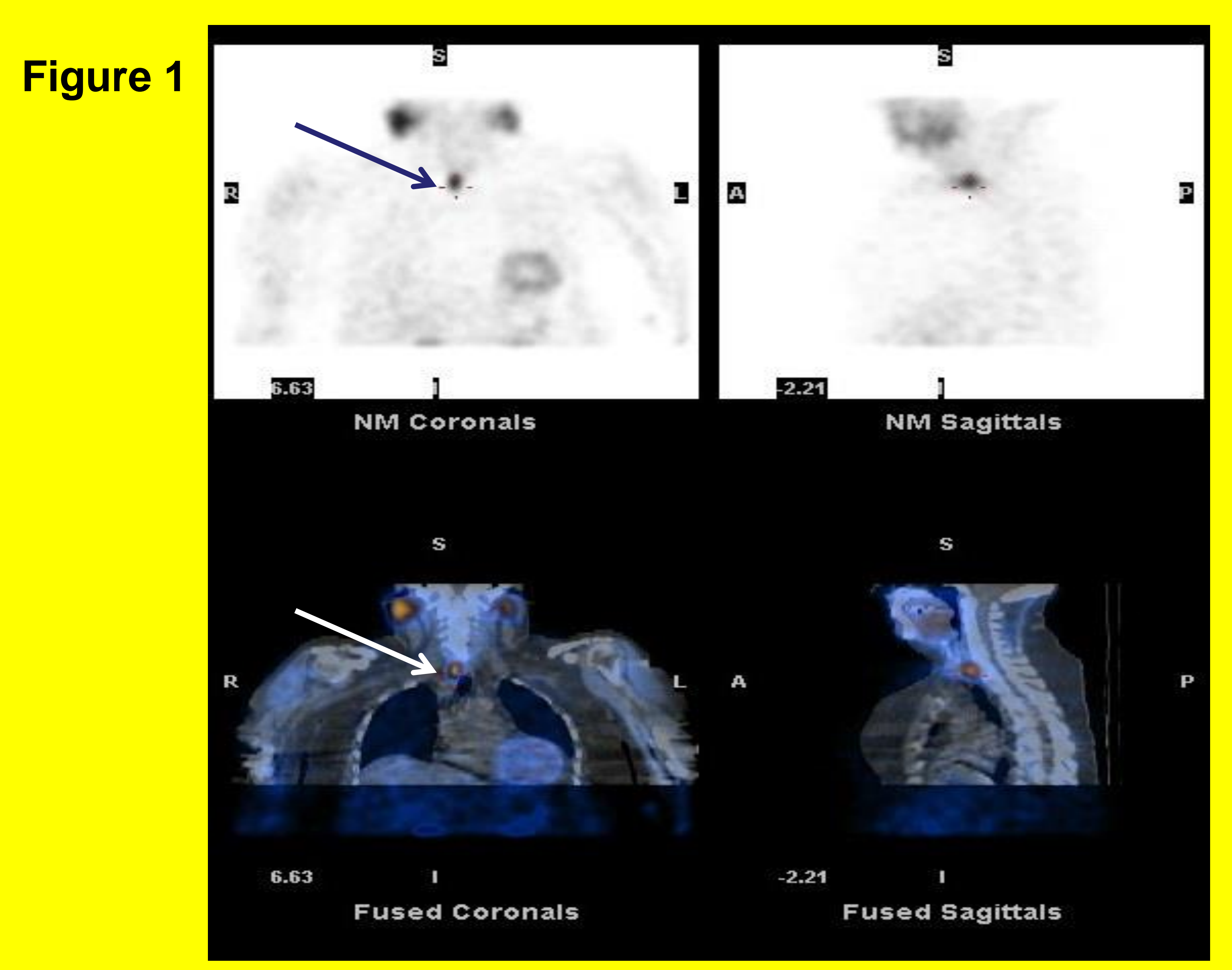

\section{CONCLUSIONS}

The coexistence of FHH and PHPT should be considered in patients with hypercalcemia, hypophosphatemia, mildly elevated parathyroid hormone levels and inappropriate hypocalciuria. Although surgical intervention may not resolve the hypercalcemia completely, it will alleviate the symptoms and prevent potential complications of the hypercalcaemia secondary to PHPT. 